\title{
HER2/HER3 pathway in biliary tract malignancies; systematic review and meta-analysis: a potential therapeutic target?
}

\author{
Salvatore Galdy ${ }^{1,2}$ - Angela Lamarca ${ }^{2}$ Mairéad G. McNamara ${ }^{2,3}$. \\ Richard A. Hubner ${ }^{2} \cdot$ Chiara A. Cella $^{1} \cdot$ Nicola Fazio $^{1} \cdot$ Juan W. Valle $^{2,3}$
}

Published online: 15 December 2016

(C) The Author(s) 2016. This article is published with open access at Springerlink.com

\begin{abstract}
Human epidermal growth factor receptor 2 (HER2) overexpression and amplification have been reported as predictive markers for HER2-targeted therapy in breast and gastric cancer, whereas human epidermal growth factor receptor 3 (HER3) is emerging as a potential resistance factor. The aim of this study was to perform a systematic review and metaanalysis of the HER2 and HER3 overexpression and amplification in biliary tract cancers (BTCs). An electronic search of MEDLINE, American Society of Clinical Oncology (ASCO), European Society of Medical Oncology Congress (ESMO), and American Association for Cancer Research (AACR) was performed to identify studies reporting HER2 and/or HER3 membrane protein expression by immunohistochemistry (IHC) and/or gene amplification by in situ hybridization (ISH) in BTCs. Studies were classified as "high quality" (HQ) if IHC overexpression was defined as presence of moderate/strong staining or "low quality" (LQ) where "any" expression was considered positive. Of 440 studies screened, 40 met the inclusion criteria. Globally, HER2 expression rate was $26.5 \%$ (95\% CI 18.9-34.1\%). When HQ studies were analyzed ( $n=27$ studies), extrahepatic BTCs showed a higher HER2 overexpression rate compared to intrahepatic cholangiocarcinoma: $19.9 \%$ (95\% CI 12.8-27.1\%) vs. $4.8 \%$ (95\% CI $0-14.5 \%)$, respectively, $p$ value 0.0049 . HER2
\end{abstract}

Juan W. Valle

juan.valle@christie.nhs.uk

1 Unit of Gastrointestinal Medical Oncology and Neuroendocrine Tumors, European Institute of Oncology, Milan, Italy

2 Department of Medical Oncology, The Christie NHS Foundation Trust, Manchester, UK

3 Institute of Cancer Sciences, Department of Medical Oncology, The Christie NHS Foundation Trust, University of Manchester, Wilmslow Road, Manchester M20 4BX, UK amplification rate was higher in patients selected by HER2 overexpression compared to "unselected" patients: $57.6 \%$ (95\% CI $16.2-99 \%$ ) vs. $17.9 \%$ (95\% CI $0.1-35.4 \%$ ), respectively, $p$ value 0.0072 . HER3 overexpression (4/4 HQ studies) and amplification rates were $27.9 \%$ (95\% CI 9.7$46.1 \%$ ) and $26.5 \%$ (one study), respectively. Up to $20 \%$ of extrahepatic BTCs appear to be HER2 overexpressed; of these, close to $60 \%$ appear to be HER 2 amplified, while HER3 is overexpressed or amplified in about $25 \%$ of patients. Clinical relevance for targeted therapy should be tested in prospective clinical trials.

Keywords Biliary tract cancer $\cdot$ Cholangiocarcinoma $\cdot$ HER2 pathway $\cdot$ HER3 pathway $\cdot$ Systematic review $\cdot$ Meta-analysis

\section{Introduction}

\subsection{Background}

The prognosis for patients with advanced biliary tract cancers (BTCs) is very poor with a median overall survival of less than 12 months following treatment with systemic chemotherapy [1]. The term BTCs refers to a heterogeneous group of diseases encompassing cholangiocarcinoma (CC) [intrahepatic cholangiocarcinoma (IHCC), extrahepatic cholangiocarcinoma (EHCC)], gallbladder carcinoma (GBC), and ampulla of Vater carcinoma (AC). It is postulated that specific genetic and molecular aberrations vary between these subtypes and thus may provide predictive biomarkers of response to targeted therapy. Unfortunately, unlike other solid tumors, targetable biomarkers are lacking in BTCs and the cisplatin and gemcitabine combination remains gold standard first-line treatment worldwide in patients with advanced disease [2], with no proven benefit from targeted therapies as yet 
identified [3, 4]. Thus, biomarkers of response are urgently required in this challenging disease. The human epidermal growth factor receptor 2 (HER2), which belongs to the $\mathrm{ErbB} /(\mathrm{HER})$ family of receptor tyrosine kinases (TK), is a well-described predictive biomarker for anti-HER2 therapy in breast and gastric cancer [5, 6]. To date, previous clinical reports have suggested some activity of trastuzumab (an antiHER 2 monoclonal antibody) in association with chemotherapy in HER2 upregulated BTCs [7-10]. In contrast, trials exploring the role of anti-EGFR monoclonal antibodies and EGFR tyrosine kinase inhibitors (TKIs) have resulted in disappointing and/or conflicting findings [11-14]. This systematic review aims to quantify the reported HER2 and HER3 expression rates in BTC in order to provide useful data for the development of potential novel systemic-targeted strategies for use in future clinical trials.

\subsection{HER2/HER3 pathway}

The HER family consists of four receptors [HER1 (EGFR), HER2, HER3, and HER4] with similar structure, consisting of four main parts: an extracellular ErbB ligand-binding domain, a single transmembrane lipophilic segment, an intracellular tyrosine kinase domain, and an intracellular C-terminal tail [15]. The extracellular ligand-binding region contains four domains (I-IV): domains I and III recognize and bind their corresponding ligands and domain II mediates receptor dimerization, whereas domain IV, interacting with domain II, leads to a negative feedback on the dimerization process [16]. Ligand binding to the extracellular domain results in receptor homo- or heterodimerization, a critical step in HER familymediated signaling. Dimerization induces the activation of the intrinsic tyrosine kinase domain, by phosphorylation of specific tyrosine residues, leading to the activation of different downstream signaling cascades, including the mitogenactivated protein kinase (MAPK) proliferation pathway and phosphatidylinositol 3-kinase (PI3K)/protein kinase B (PKB or Akt) pro-survival pathway [17, 18] (Fig. 1).

HER 2 and HER 3 are known to have characteristics distinct from other HER family receptors. HER2 lacks a specific ligand, so it can form heterodimers only if it is trans-activated from other activated HER receptors (such as EGFR, HER3, and HER4) [19]. In addition to abnormal overexpression, HER2 is also able to spontaneously homodimerize [16]. In contrast to HER2, HER3 can bind multiple ligands (neuregulins) [20] but it lacks a functioning kinase domain [21] and is, therefore, unable to homodimerize and to induce downstream signaling pathway activation on its own. However, in the presence of HER3 ligands, HER3 may promote the kinase activity of EGFR or HER2 and thereby induce phosphorylation of the HER3 C-terminal tail inducing the PI3K/Akt pathway activation by creating heterodimers [20]. Although all four HER family receptors are capable of dimerizing with each other, HER2 is the preferred dimerization partner [19] and the HER2-HER3 dimer seems to be the most potent HER family dimer [22, 23]. Finally, HER3 has the ability to dimerize with both HER family members and nonHER family members such as mesenchymal epithelial transition (MET) receptor [24, 25], contributing to anti-HER2 therapy resistance. Thus, dysregulation of HER-mediated signaling pathways, through this complex mechanism, results in the growth and spread of cancer cells.

\subsection{HER2 and HER3 determination}

The most commonly used methods to determine the HER2 and HER3 status, in formalin-fixed paraffin-embedded tissue, are (a) immunohistochemistry (IHC), which measures the number of HER 2 and HER 3 receptors on the cell surface and therefore detects receptor overexpression and (b) fluorescence or chromogenic in situ hybridization (FISH and CISH, respectively), which detects gene amplification by measuring the number of copies of the HER 2 and HER 3 gene in the nuclei of tumor cells.

Currently, standard clinical practice guidelines for HER2 status assessment are available for breast and gastric cancer only. In contrast, because HER3 status is not routinely analyzed, IHC and ISH techniques for assessing HER3 status have not been standardized.

The IHC and FISH scoring criteria are different for breast and gastric cancer [26, 27], reflecting intrinsic biological differences, including higher heterogeneity of HER2 membranous immunoreactivity in gastric cancer. In addition, in gastric cancer, different scales are used depending on the nature of the diagnostic specimen (surgical specimen vs. biopsy sample) $[6,27]$; these criteria are summarized in Table 1.

Data from published series of HER2 and HER3 expression varies both in terms of methodology, reporting, and subsequent utility. We therefore set out to undertake a systematic review (i.e., pooled analysis of HER 2 and HER 3 expression in published BTC series), to provide a "summary estimate" of such expression, with a view to informing the design of future clinical trials.

\section{Methods}

\subsection{Study selection criteria}

Eligible studies were those which met the following inclusion criteria: (1) studies reporting membrane expression by IHC and/or amplification by ISH of HER2 and/or HER3 data in human BTC tissue; (2) studies in which data for invasive/ infiltrating tumors was available; and (3) original article publications (or abstracts, in the absence of a full publication); studies reporting preclinical data, reviews, and case reports were excluded. Studies in which data for the subgroup of patients 
Fig. 1 HER2/HER3 pathway and targeted therapy interaction

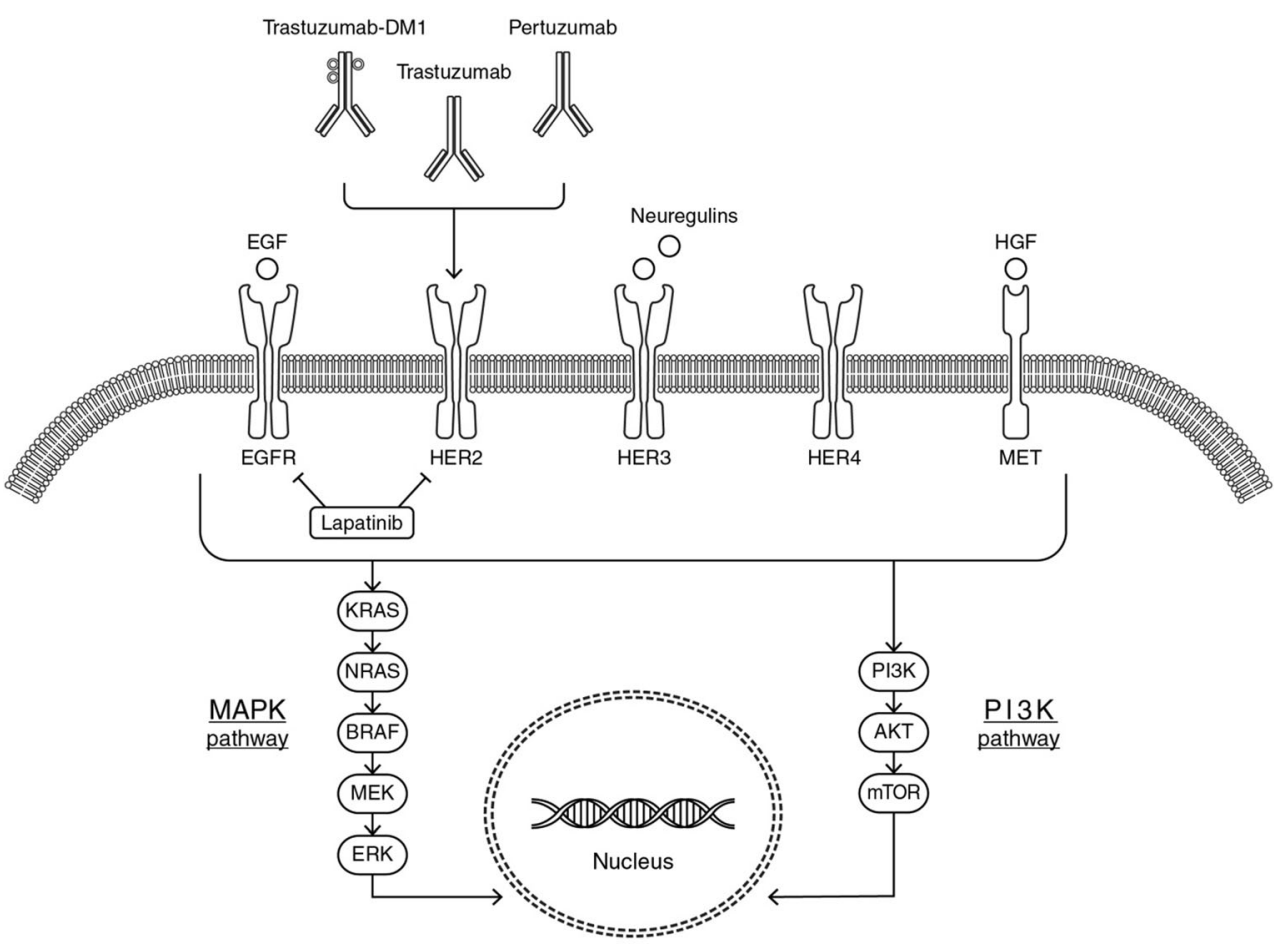

with BTC was not available (i.e., when only combined results were reported including non-BTC primary disease sites such as hepatocellular carcinoma, pancreatic carcinoma, or neuroendocrine tumors) were excluded. Other exclusion criteria were (1) studies reporting results which included mixed pathological entities [i.e., mixed hepato-cholangiocarcinoma, mixed adenoneuroendocrine carcinomas (MANEC)]; (2) publications in which techniques other than IHC and ISH were employed (with no data for IHC or ISH available); and (3) studies in which HER2 pathway analysis was performed following successful anti-HER2 therapy were excluded due to patient selection bias. When studies reporting the same series of patients were identified ("duplicate data"), the study with the greater number of informative patients for the primary end point of this review was selected for inclusion.

\subsection{Search strategy}

A systematic search was conducted utilizing the PubMed/ MEDLINE electronic data base (updated 20 November 2015); no dates of publication or language limits were applied. The following two search strategies were employed:

1. her2[All Fields] AND ((“cholangiocarcinoma"[MeSH Terms] OR "cholangiocarcinoma"[All Fields]) OR (("biliary tract"[MeSH Terms] OR ("biliary"[All Fields] AND "tract”[All Fields]) OR "biliary tract"[All Fields]) AND ("carcinoma"[MeSH Terms] OR "carcinoma"[All Fields])) OR ((“gallbladder"[MeSH Terms] OR "gallbladder"[All Fields]) AND ("carcinoma"[MeSH
Terms] OR “carcinoma”[All Fields])) OR (ampullary[All Fields] AND ("carcinoma"[MeSH Terms] OR "carcinoma"[All Fields])) OR (("carcinoma"[MeSH Terms] OR "carcinoma”[All Fields]) AND ("ampulla of vater"[MeSH Terms] OR ("ampulla"[All Fields] AND “vater"[All Fields]) OR “ampulla of vater"[All Fields])));

2. her3[All Fields] AND ((“cholangiocarcinoma”[MeSH Terms] OR "cholangiocarcinoma"[All Fields]) OR ((“biliary tract”[MeSH Terms] OR ("biliary"[All Fields] AND "tract”[All Fields]) OR "biliary tract”[All Fields]) AND ("carcinoma"[MeSH Terms] OR "carcinoma"[All Fields])) OR ((“gallbladder"[MeSH Terms] OR "gallbladder"[All Fields]) AND ("carcinoma"[MeSH Terms] OR "carcinoma"[A1l Fields])) OR (ampullary[All Fields] AND ("carcinoma"[MeSH Terms] OR "carcinoma"[All Fields])) OR (("carcinoma"[MeSH Terms] OR "carcinoma"[All Fields]) AND ("ampulla of vater"[MeSH Terms] OR ("ampulla"[All Fields] AND "vater"[All Fields]) OR "ampulla of vater"[All Fields]))) OR (("receptor, erbb2"[MeSH Terms] OR "genes, erbb-2"[MeSH Terms]) AND ((("cholangiocarcinoma"[MeSH Terms] OR "cholangiocarcinoma"[All Fields]) OR (("biliary tract"[MeSH Terms] OR ("biliary"[All Fields] AND "tract"[All Fields]) OR "biliary tract"[All Fields]) AND ("carcinoma"[MeSH Terms] OR "carcinoma"[All Fields])) OR (("gallbladder"[MeSH Terms] OR "gallbladder"[All Fields]) AND ("carcinoma"[MeSH Terms] OR "carcinoma"[All Fields])) OR (ampullary[All Fields] AND ("carcinoma"[MeSH 
Table 1 Standardized guidelines for HER2 analysis, adjusted from 2013 ASCO/CAP guidelines for the HercepTest ${ }^{\mathrm{TM}}$ scoring system in breast cancer [26] and standardized guidelines (for both surgical and biopsy specimen) for gastric adenocarcinoma [6, 27]

\begin{tabular}{|c|c|c|c|c|}
\hline & $0+($ negative $)$ & 1+ (weak; negative) & $\begin{array}{l}2+\text { (moderate; } \\
\text { equivocal) }\end{array}$ & $\begin{array}{l}3+\text { (strong; } \\
\text { positive) }\end{array}$ \\
\hline \multicolumn{5}{|l|}{$\begin{array}{l}\text { HER2 } \\
\quad \text { expression } \\
\text { (IHC) }\end{array}$} \\
\hline Breast cancer & $\begin{array}{l}\text { No staining observed } \\
\text { or membrane } \\
\text { staining that is } \\
\text { incomplete and is } \\
\text { faint/barely per- } \\
\text { ceptible and with- } \\
\text { in } \leq 10 \% \text { of the } \\
\text { invasive tumor } \\
\text { cells }\end{array}$ & $\begin{array}{l}\text { Incomplete } \\
\text { membrane } \\
\text { staining that is } \\
\text { faint/barely per- } \\
\text { ceptible and with- } \\
\text { in }>10 \% \text { of the } \\
\text { invasive tumor } \\
\text { cells }\end{array}$ & $\begin{array}{l}\text { Circumferential } \\
\text { membrane } \\
\text { staining that is } \\
\text { incomplete and/or } \\
\text { weak/moderate } \\
\text { and within }>10 \% \\
\text { of the invasive tu- } \\
\text { mor cells or com- } \\
\text { plete and circum- } \\
\text { ferential mem- } \\
\text { brane staining that } \\
\text { is intense and } \\
\text { within } \leq 10 \% \text { of } \\
\text { the invasive tumor } \\
\text { cells }\end{array}$ & $\begin{array}{l}\text { Circumferential } \\
\text { membrane } \\
\text { staining that is } \\
\text { complete and } \\
\text { intense in }>10 \% \\
\text { of the cancerous } \\
\text { cells }\end{array}$ \\
\hline $\begin{array}{l}\text { Gastric } \\
\text { cancer; } \\
\text { surgical } \\
\text { specimens }\end{array}$ & $\begin{array}{l}\text { No reactivity or } \\
\text { membranous } \\
\text { reactivity in } \\
<10 \% \text { of cells }\end{array}$ & $\begin{array}{l}\text { Faintbarely } \\
\text { perceptible } \\
\text { membranous } \\
\text { reactivity in } \\
>10 \% \text { of cells; } \\
\text { cells are reactive } \\
\text { only in part of } \\
\text { their membrane }\end{array}$ & $\begin{array}{l}\text { Weak to moderate } \\
\text { complete or } \\
\text { basolateral } \\
\text { membranous } \\
\text { reactivity in } \\
>10 \% \text { of tumor } \\
\text { cells }\end{array}$ & $\begin{array}{l}\text { Moderate to strong } \\
\text { complete or } \\
\text { basolateral } \\
\text { membranous } \\
\text { reactivity in } \\
>10 \% \text { of tumor } \\
\text { cells }\end{array}$ \\
\hline $\begin{array}{l}\text { Gastric } \\
\text { cancer; } \\
\text { biopsy } \\
\text { specimens }\end{array}$ & $\begin{array}{l}\text { No reactivity or no } \\
\text { membranous } \\
\text { reactivity in any } \\
\text { tumor cell }\end{array}$ & $\begin{array}{l}\text { Faint/barely } \\
\text { perceptible } \\
\text { membranous } \\
\text { reactivity } \\
\text { irrespective of } \\
\text { percentage of } \\
\text { tumor cells }\end{array}$ & $\begin{array}{l}\text { Weak to moderate } \\
\text { complete, } \\
\text { basolateral or } \\
\text { lateral } \\
\text { membranous } \\
\text { reactivity } \\
\text { irrespective of } \\
\text { percentage of } \\
\text { tumor cells }\end{array}$ & $\begin{array}{l}\text { Strong complete, } \\
\text { basolateral or } \\
\text { lateral } \\
\text { membranous } \\
\text { reactivity } \\
\text { irrespective of } \\
\text { percentage of } \\
\text { tumor cells }\end{array}$ \\
\hline \multicolumn{5}{|l|}{$\begin{array}{l}\text { HER2 } \\
\text { amplifica- } \\
\text { tion (ISH) }\end{array}$} \\
\hline Breast cancer & \multicolumn{4}{|c|}{$\begin{array}{l}\text { HER } 2 \text { FISH testing (gene copy number and HER2-to-CEP17 ratio) positive: HER2 gene copy } \\
\text { number is greater than } 6.0 \text { (single probe) and in case of HER } 2+\text { if either HER2/CEP17 ratio } \\
\text { is } \geq 2.0 \text { regardless gene copy number or if HER2/CEP17 ratio is }<2.0 \text { with an average HER } 2 \\
\text { copy number } \geq 6.0 \text { (dual probe) }\end{array}$} \\
\hline $\begin{array}{l}\text { Gastric } \\
\text { cancer }\end{array}$ & \multicolumn{4}{|c|}{$\begin{array}{l}\text { FISH amplified (positive): IHC/HER2 } 2+\text { tumor samples are considered FISH amplified if } \\
\text { HER2/CEP17 ratio is } \geq 2\end{array}$} \\
\hline
\end{tabular}

IHC immunohistochemistry, ISH in situ hybridization
Terms] OR "carcinoma"[All Fields]))) OR (("carcinoma"[MeSH Terms] OR "carcinoma"[All Fields]) AND ("ampulla of vater"[MeSH Terms] OR ("ampulla"[All Fields] AND "vater"[All Fields]) OR "ampulla of vater"[All Fields])))).

Meeting abstracts from the American Society of Clinical Oncology (ASCO), European Society of Medical Oncology Congress (ESMO), and American Association for Cancer Research (AACR), presented over the last 5 years (20102015), were also reviewed using the following keywords: "her2" OR "her3" AND ("cholangiocarcinoma," "biliary tract carcinoma," "gallbladder carcinoma," "ampullary carcinoma," "carcinoma of ampulla of vater").

Reference lists of eligible studies were cross-checked manually to identify potentially eligible articles.

\subsection{Primary and secondary objectives}

The primary objective of this systematic review and metaanalysis was to assess the prevalence of HER 2 overexpression 
(measured by IHC) in patients with BTC, with the primary end point being mean HER2 expression rate.

Secondary objectives included HER2 amplification (measured by ISH) both in the whole population ("unselected population") and in the population of patients with HER2 overexpression by IHC ("selected population") and HER3 overexpression (measured by IHC) and amplification (measured by ISH). HER2 and HER 3 expression and amplification were analyzed by primary tumor site; HER2 expression was also analyzed by quality of expression assessment ("high quality" vs. "low quality") and by region (Western vs. Asian). Correlation between HER2 and HER3 expression and between HER2 expression and HER2 amplification (in "unselected population") was also assessed.

\subsection{Data collection}

Eligibility for each of the studies was assessed by one of the authors (SG); queries were discussed with a second author (AL). Same process was followed for data collection. The total number of patients in each study together with numerator and denominator for each one of the reported rates were collected.

In order to perform the planned subgroup analyses, the following additional data were extracted from manuscripts (if available): primary site (CC, IHCC, EHCC, GBC, or AC) and ethnicity/region of patients involved in the study (Western vs. Asian). Tumor site was also subdivided into extrahepatic BTCs (EH-BTCs) which include EHCC, GBC, and AC and IHCC. In addition, eligible studies were classified according to the quality of HER expression assessment: studies were considered to be "high quality" (HQ) when moderate/strong HER2/HER3 overexpression was used to classify tumors, whereas studies were classified as "low quality" (LQ) when the HER2/HER3 overexpression threshold was not specified and/or not reported by authors or when "any" HER2/HER3 expression (including IHC 1+) was used.

For assessment of HER2 amplification rate, studies were classified according to the population in which ISH was performed: "unselected population" referred to studies in which the ISH was performed in the whole study population regardless of IHC results, while the term "selected population" was employed for those studies in which ISH was performed only in patients with overexpression of HER2 according to IHC.

\subsection{Statistical analysis}

The Stata/MP v.12 package was used for the statistical analysis. Mean and $95 \%$ confidence intervals $(95 \% \mathrm{CI})$ were calculated for reported HER2/HER3 expression/amplification rate. Mean HER2/HER3 expression/amplification rates were calculated for each one of the prespecified subgroup analyses: primary tumor site, region, quality of HER2 expression assessment, and population in which ISH was performed. All these analyses were repeated for each one of the tumor sites. Shapiro-Wilks normality test was performed for continuous variables; based on these results, parametric/ nonparametric tests were used for the statistical analysis of the results and comparison of expression/amplification rates between subgroups employing Student's $t$ test or Wilcoxon rank-sum test as appropriate. Correlation was assessed using Pearson or Spearman's rho as appropriate, according to whether variables followed a normal distribution or not.

\section{Results}

\subsection{Eligible studies}

Figure 2 summarizes the PRISMA flow diagram for selection of eligible studies [28]; a total of 454 results were obtained from the searches in PubMed/MEDLINE $(n=105)$, ASCO $(n=11), \operatorname{ESMO}(n=103)$, and AACR $(n=235)$. Of these, 14 were duplicates and 389 did not meet the inclusion criteria and were therefore excluded. Of the 51 studies which appeared to be eligible after the initial screen, a full-text search was carried out. In addition, seven full-text records through crossreference checking were identified for a total of 58 studies assessable for eligibility. Eighteen studies were excluded after the full-text review as per our inclusion/exclusion criteria: 11 studies did not report an optimal distinction between cytoplasmic and membrane HER2/HER3 staining [29-39]; one study employed a method other than IHC and/or ISH for evaluating HER2/HER3 expression with no IHC/ISH data reported [40]; three studies reported HER2 analysis following successful targeting therapy and were therefore excluded due to selection bias [10, 41, 42]; one study reported joined results for BTCs and pancreatic cancer with no specific data for BTC patients [43]; one study did not report which member of the HER family was being assessed [44]; and one study reported "duplicate data" [45].

\subsection{Patient population}

Forty studies were included in the final analysis, reporting a total of 3839 patients with a diagnosis of BTC [46-85] (Table 2). All studies were retrospective series, with a median number of 53 patients per study (range 6-804).

According to the primary tumor site, the number of studies and number of patients reported were as follows: CC (24 studies; 2102 patients; $55 \%$ of all patients reported), IHCCs (13 studies; 924 patients; $24 \%$ of all patients reported; $44 \%$ of all CC patients), EHCCs (12 studies; 920 patients; $24 \%$ of all patients reported; $44 \%$ of all CC patients), GBCs (15 studies; 1026 patients; $27 \%$ of all patients reported), and ACs (8 studies; 303 patients; $8 \%$ of all patients reported). In seven 
Fig. 2 PRISMA flow diagram

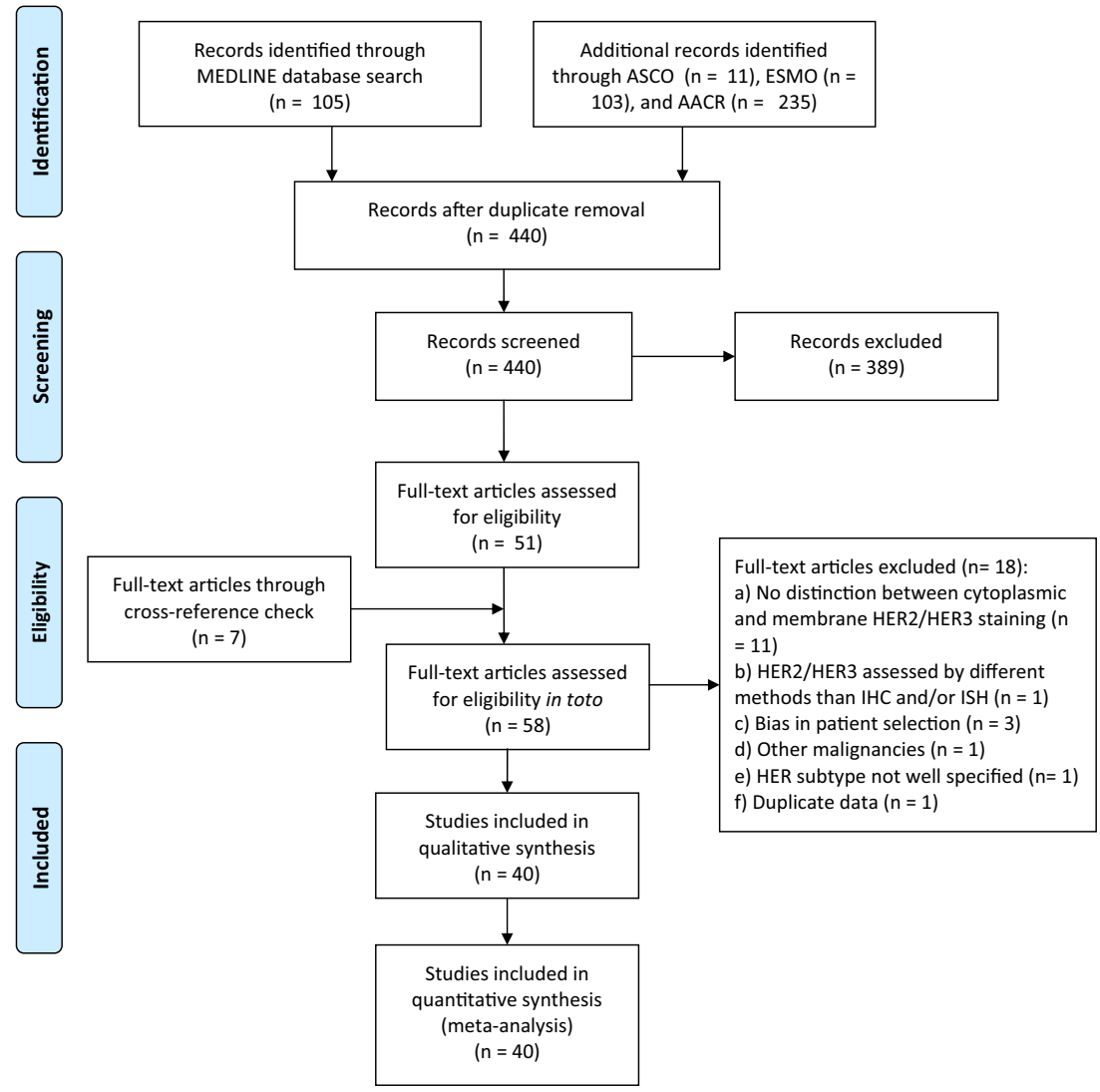

studies (258 patients; $7 \%$ of all patients reported; $12 \%$ of all $\mathrm{CC}$ patients), the type of CC (IHCC vs. EHCC) was not specified. In four studies (408 patients; $10 \%$ of all patients reported), the type of BTC was not specified. Eighteen out of 40 (45\%) studies were conducted in Western countries and 17 (43\%) in Asian population, while the remaining 5 (12\%) studies were mixed or not specified (Table 2).

\subsection{HER2 expression (IHC)}

Thirty-eight studies reported HER2 positivity assessed by IHC (Table 3); two studies did not perform HER2 IHC analysis $[66,85]$. Technical details regarding this assessment were available for 37 of the 38 studies: in the remaining study, this data was not available [71]. The most commonly used (23 of 37 studies; $62 \%$ ) anti-HER2 antibody was polyclonal (Dako®, Dakopatts®, Nichirei®, or Zymed Lab®), followed by monoclonal antibody in 13 studies (35\%) (Triton Biosciences Inc. ${ }$, Immunotech $\AA$, DAKO $®$, Oncogene $\AA$, Zymed Lab®, Carpinteria ${ }^{\circledR}$, Ventana ${ }^{\circledR}$, or Novocastra $\left.{ }^{\circledR}\right)$; this information was not available in one study (3\%). HER2 expression was qualitatively analyzed in 5 out of 37 (14\%) studies, while a semiquantitative score, estimating the fraction of positive cells, was used in 32 studies (86 \%) (Table 3 ).

Globally, the mean HER2 expression rate was $26.5 \%$ (95\% CI, 18.9-34.1\%; Table 4). There were no statistically significant differences between regions (Asian mean HER2 expression rate $28.4 \%$ (95\% CI 14.5-42.3\%) vs. Western $19.7 \%$ (95 \% CI 10.1-29.2\%); $p$ value 0.4936; Table 4). With respect to the quality of HER2 expression assessment, LQ studies (11 studies; $27 \%$ of all studies reporting HER2-IHC data) had a significantly higher mean HER2 expression rate compared to HQ studies (27 studies; $68 \%$ of all studies reporting HER2-IHC data): $41.7 \%$ (95 \% CI 22.9-60.5\%) vs. $20.3 \%$ (95 \% CI 13.3-27.4\%), respectively, $p$ value 0.0336 ; Table 4.

In all 38 studies, no differences in HER2/IHC expression rates were found between tumor sites when considering all studies, regardless of the quality of HER2 expression assessment (Table 4). In contrast, when only HQ studies were considered, the mean HER2 overexpression rate in EH-BTCs was statistically significantly higher to IHCCs (Table 4). Moreover, mean HER2 overexpression rate was statistically significantly higher in EHCCs compared to IHCCs and in GBCs compared to IHCCs, whereas there was only a marginal difference between ACs and IHCCs (Table 4).

\subsection{HER2 amplification (ISH)}

HER2 amplification analysis was performed in 16 studies: applying FISH and CISH in 13 (81\%) and 3 (19\%) studies, respectively (Table 3). Mean HER2 amplification rate was 
Table 2 HER2 and/or HER3 expression by immunohistochemistry (IHC) and/or amplification by in situ hybridization (ISH) in biliary tract carcinomas

\begin{tabular}{|c|c|c|c|c|c|c|c|c|c|c|c|}
\hline \multirow[t]{2}{*}{ Study } & \multirow[t]{2}{*}{ Country } & \multirow[t]{2}{*}{$N$} & \multirow[t]{2}{*}{ Primary } & \multicolumn{2}{|c|}{ HER2/IHC } & \multicolumn{2}{|c|}{ HER2/ISH } & \multicolumn{2}{|c|}{ HER3/IHC } & \multicolumn{2}{|c|}{ HER3/ISH } \\
\hline & & & & $N$ & $\%$ & $N$ & $\%$ & $N$ & $\%$ & $N$ & $\%$ \\
\hline Brunt EM & USA (Western) & 6 & $\mathrm{CC}$ & $4 / 6$ & 66.7 & NR & & NR & & NR & \\
\hline Collier JD 1992 & UK (Western) & 10 & $\mathrm{CC}$ & $0 / 10$ & 0 & NR & & NR & & NR & \\
\hline Lei S 1995 & USA (Western) & 6 & $\mathrm{AC}$ & $2 / 6$ & 33.3 & NR & & NR & & NR & \\
\hline \multirow[t]{3}{*}{ Chow NH 1995} & Taiwan (China) (Asian) & 18 & IHCC & $5 / 18$ & 27.8 & NR & & NR & & NR & \\
\hline & & 18 & $\mathrm{AC}$ & $5 / 18$ & 27.8 & NR & & NR & & NR & \\
\hline & & 11 & GBC & $7 / 11$ & 63.6 & NR & & NR & & NR & \\
\hline \multirow[t]{2}{*}{ Vaidya P 1996} & Japan (Asian) & 14 & EHCC & $10 / 14$ & 71.4 & NR & & $4 / 14$ & 28.6 & NR & \\
\hline & & 13 & $\mathrm{AC}$ & $9 / 13$ & 69.2 & NR & & $4 / 13$ & 30.8 & NR & \\
\hline Terada T 1998 & Japan (Asian) & 47 & $\mathrm{CC}$ & $33 / 47$ & 70 & NR & & NR & & NR & \\
\hline Kim YW 2001 & Not specified & 71 & GBC & $33 / 71$ & 46.5 & NR & & NR & & NR & \\
\hline Ajiki T 2001 & Japan (Asian) & 30 & $\mathrm{AC}$ & $7 / 30$ & 23 & NR & & NR & & NR & \\
\hline Ukita Y 2002 & Japan (Asian) & 22 & IHCC & $18 / 22$ & 82 & $22 / 22$ & 100 & NR & & NR & \\
\hline Endo K 2002 & Japan, Thailand, USA (n/a) & 71 & $\mathrm{CC}$ & $21 / 71$ & 29.6 & NR & & NR & & NR & \\
\hline Altimari A 2003 & Italy (Western) & 48 & IHCC & $2 / 48$ & 4 & $2 / 48$ & 4 & NR & & NR & \\
\hline Matsuyama S 2004 & Japan (Asian) & 43 & GBC & $4 / 43$ & 9.4 & NR & & NR & & NR & \\
\hline KIM HJ 2005 & South Korea (Asian) & 20 & $\mathrm{CC}$ & $5 / 20$ & 25 & NR & & NR & & NR & \\
\hline \multirow[t]{6}{*}{ Nakazawa K 2005} & Japan (Asian) & 28 & IHCC & $0 / 28$ & 0 & NR & & NR & & NR & \\
\hline & & 78 & $\mathrm{EHCC}$ & $4 / 78$ & 5.1 & NR & & NR & & NR & \\
\hline & & 89 & GBC & $14 / 89$ & 15.7 & NR & & NR & & NR & \\
\hline & & 26 & AV & $3 / 26$ & 11.5 & NR & & NR & & NR & \\
\hline & & 71 & BTC & - & & $15 / 71$ & 21.1 & - & & - & \\
\hline & & 19 & BTC & - & & $15 / 19$ & 79 & - & & - & \\
\hline Settakorn J 2005 & Australia/Thailand (n/a) & 31 & IHCC & $10 / 31$ & 32.3 & NR & & NR & & NR & \\
\hline Ogo Y 2006 & Japan (Asian) & 72 & BTCs & $47 / 72$ & 65 & NR & & NR & & NR & \\
\hline Kim JH 2007 & South Korea (Asian) & 55 & EHCC & $16 / 55$ & 29.1 & $10 / 55$ & 18.1 & NR & & NR & \\
\hline \multirow[t]{3}{*}{ Kawamoto T 2007} & USA/Chile (Western) & 21 & IHCC & $7 / 21$ & 33.3 & $0 / 14$ & 0 & NR & & NR & \\
\hline & & 16 & EHCC & $5 / 16$ & 33.3 & $3 / 14$ & 21.4 & NR & & NR & \\
\hline & & 77 & GBC & $24 / 77$ & 31.2 & $14 / 67$ & 20.9 & NR & & NR & \\
\hline \multirow[t]{2}{*}{ Yoshikawa D 2008} & Japan (Asian) & 106 & IHCC & $1 / 106$ & 0.9 & NR & & NR & & NR & \\
\hline & & 130 & $\mathrm{EHCC}$ & $11 / 130$ & 8.5 & NR & & NR & & NR & \\
\hline Miyahara n 2008 & Japan (Asian) & 51 & GBC & $16 / 51$ & 31 & $4 / 16$ & 25 & NR & & NR & \\
\hline Joo HH 2007 & South Korea (Asian) & 112 & BTCs & $5 / 112$ & 4.5 & NR & & NR & & NR & \\
\hline Puhalla H 2007 & Austria (Western) & 55 & GBC & $7 / 55$ & 13 & NR & & NR & & NR & \\
\hline Kaufmann M 2008 & USA (Western) & 16 & GBC & $1 / 16$ & 6.3 & NR & & NR & & NR & \\
\hline Baumhoer D 2008 & Switzerland, Germany, Italy (Western) & 82 & AV & NR & & $5 / 82$ & 6 & NR & & NR & \\
\hline Choi HJ 2009 & Not specified & 50 & IHCC & $36 / 50$ & 72 & NR & & NR & & NR & \\
\hline \multirow[t]{2}{*}{ Aloysius MM 2009} & UK (Western) & 29 & EHCC & $0 / 29$ & 0 & NR & & NR & & NR & \\
\hline & & 22 & AV & $0 / 22$ & 0 & NR & & NR & & NR & \\
\hline Harder J 2009 & Germany (Western) & 124 & BTCs & $25 / 124$ & 20.2 & $6 / 25$ & 24 & NR & & NR & \\
\hline \multirow[t]{3}{*}{ Shafizadeh N 2010} & USA (Western) & 26 & IHCC & $0 / 26$ & 0 & NR & & NR & & NR & \\
\hline & & 19 & EHCC & $2 / 19$ & 10.5 & NR & & NR & & NR & \\
\hline & & 6 & GBC & $0 / 6$ & 0 & NR & & NR & & NR & \\
\hline \multirow[t]{3}{*}{ Pignochino Y 2010} & Italy (Western) & 17 & IHCC & $0 / 10$ & 0 & NR & & NR & & NR & \\
\hline & & 19 & EHCC & $4 / 19$ & 21 & $2 / 4$ & 50 & NR & & NR & \\
\hline & & 13 & GBC & $1 / 10$ & 10 & $1 / 1$ & 100 & NR & & NR & \\
\hline Toledo C 2012 & Chile (Western) & 12 & GBC & $4 / 12$ & 33 & $0 / 12$ & 0 & NR & & NR & \\
\hline
\end{tabular}


Table 2 (continued)

\begin{tabular}{|c|c|c|c|c|c|c|c|c|c|c|c|}
\hline \multirow[t]{2}{*}{ Study } & \multirow[t]{2}{*}{ Country } & \multirow[t]{2}{*}{$N$} & \multirow[t]{2}{*}{ Primary } & \multicolumn{2}{|c|}{ HER2/IHC } & \multicolumn{2}{|c|}{ HER2/ISH } & \multicolumn{2}{|c|}{ HER3/IHC } & \multicolumn{2}{|c|}{ HER3/ISH } \\
\hline & & & & $N$ & $\%$ & $N$ & $\%$ & $N$ & $\%$ & $N$ & $\%$ \\
\hline Kumari N 2012 & India (Asian) & 104 & GBC & $14 / 104$ & 13.4 & NR & & NR & & NR & \\
\hline Lee HJ 2012 & South Korea (Asian) & 230 & EHCC & $13 / 224$ & 6 & NR & & $90 / 230$ & 39 & NR & \\
\hline Roa Iván 2013 & Chile (Western) & 187 & GBC & $62 / 187$ & 31.11 & NR & & NR & & NR & \\
\hline \multirow[t]{2}{*}{ Wang W 2014} & China (Asian) & 58 & IHCC & $0 / 90$ & 0 & $0 / 90$ & 0 & NR & & NR & \\
\hline & & 94 & $\mathrm{EHCC}$ & $4 / 90$ & 4.4 & $3 / 94$ & 3.5 & NR & & NR & \\
\hline Graham RP 2014 & USA (Western) & 100 & BTCs & $3 / 100$ & 3 & $3 / 3$ & 100 & NR & & NR & \\
\hline \multirow[t]{2}{*}{ Yang X 2014} & China (Asian) & 65 & $\mathrm{IHCC}$ & $0 / 65$ & 0 & $0 / 65$ & 0 & $8 / 65$ & 12.3 & NR & \\
\hline & & 110 & $\mathrm{EHCC}$ & $5 / 110$ & 4.5 & $8 / 108$ & 7.4 & $13 / 110$ & 11.8 & NR & \\
\hline \multirow[t]{2}{*}{ Kawamoto T 2015} & USA & 47 & $\mathrm{GBC}$ & $15 / 47$ & 32 & $8 / 47$ & 17 & $16 / 47$ & 34 & $12 / 47$ & 26 \\
\hline & Japan (n/a) & 66 & $\mathrm{CC}$ & $15 / 66$ & 23 & $15 / 66$ & 23 & $19 / 66$ & 29 & $18 / 66$ & 27 \\
\hline Hechtman J 2015 & USA (Western) & 106 & $\mathrm{AC}$ & $27 / 106$ & 25.5 & $13 / 100$ & 13 & NR & & NR & \\
\hline Oliveira Fernandes VT 2015 & Brazil (Western) & 38 & $\mathrm{CC}$ & $11 / 38$ & 30 & NR & & NR & & NR & \\
\hline \multirow[t]{3}{*}{ Holcombe RF 2015} & USA (Western) & 126 & EHCC & NR & & NR & 18 & NR & & NR & \\
\hline & & 434 & IHCC & NR & & NR & 1.5 & NR & & NR & \\
\hline & & 244 & GBC & NR & & NR & 15 & NR & & NR & \\
\hline
\end{tabular}

$C C$ cholangiocarcinoma, $I H C C$ intrahepatic cholangiocarcinoma $E H C C$ extrahepatic cholangiocarcinoma, $G B C$ gallbladder carcinoma, $A C$ carcinoma of ampulla of Vater, BTCs biliary tract carcinomas, NR not reported, $n / a$ not applicable

$30.1 \%$ (95 \% CI 11.7-48.5\%) when all BTCs were analyzed together (Table 4). When all studies were included (regardless of applying ISH for "selected" or "unselected" population), mean HER2 amplification rate was statistically significantly higher in patients with EH-BTCs compared to IHCCs (Table 4). Interestingly, the mean HER2 amplification rate was higher in the five studies $[59,68,72,73,78]$ in which ISH test was performed in "selected" population when compared to the 12 studies in which ISH test was applied to "unselected population" only [17.9 \% (95\% CI 0.1-35.4\%) vs. $57.6 \%$ (95\% CI 16.2-99\%), $p$ value 0.0072$]$ [55, 56, 59, 63, 64, 66, 77, 80-83, 85] (Table 4). Nakazawa et al. reported data from 221 patients, 71 of whom had FISH testing performed: meaningful differences in HER2 amplification rate were shown between "unselected" [15/71 (21\%)] and "selected" [15/19 (79 \%)] populations [59] (Table 2).

\subsection{Correlation between HER2 expression and amplification}

Ten studies $[55,56,59,63,64,77,80,82,83,85]$ and five studies $[59,68,72,73,78]$ had data for both HER2 expression and amplification in the "unselected" and "selected" population, respectively. While no statistically significant correlation was observed in studies with the "selected" population (five studies; Spearman rho $=-0.9 ; p$ value 0.037 ), a better correlation (although not statistically significant) was shown in "unselected" patients (10 studies; Spearman rho 0.38; $p$ value 0.2763) (Fig. 3).

\subsection{HER3 expression and amplification}

HER3 expression rate was reported in four studies in which different commercially available antibodies were used (Novocastra ${ }^{\circledR}$, Santa Cruz ${ }^{\circledR}$, or Spring Bioscience ${ }^{\circledR}$ ). All four studies had a HQ HER3 expression assessment (Table 3). The pooled mean overall HER3 overexpression rate was $27.9 \%$ (95\% CI 9.7-46.1\%) [51, 76, 81, 83]; only one study reported HER3 amplification rate (26.5\%) [83] (Table 2).

Further subgroup analyses for HER3 expression and amplification were not possible due to limited number of studies.

\subsection{Correlation between HER2 and HER3 overexpression}

All of the four studies with HER3 expression data had HER2 expression data available for correlation analysis [51, 76, 81, 83]. No statistically significant correlation was identified between HER2 and HER3 overexpression (four studies; Spearman rho $=0.2 ; p$ value 0.8 ) (Fig. 4).

\section{Discussion}

The present systematic review and meta-analysis found that there is a higher moderate/strong HER2 expression rate $(\sim 20 \%)$ in extrahepatic biliary tract carcinomas than in IHCC $(<5 \%)$. In a previous meta-analysis, Wiggers et al. also reported a statistically significant higher expression of HER2 in EHCC [risk ratio $0.22(95 \% \mathrm{CI}, 0.07-0.65)$ ] than in IHCC 


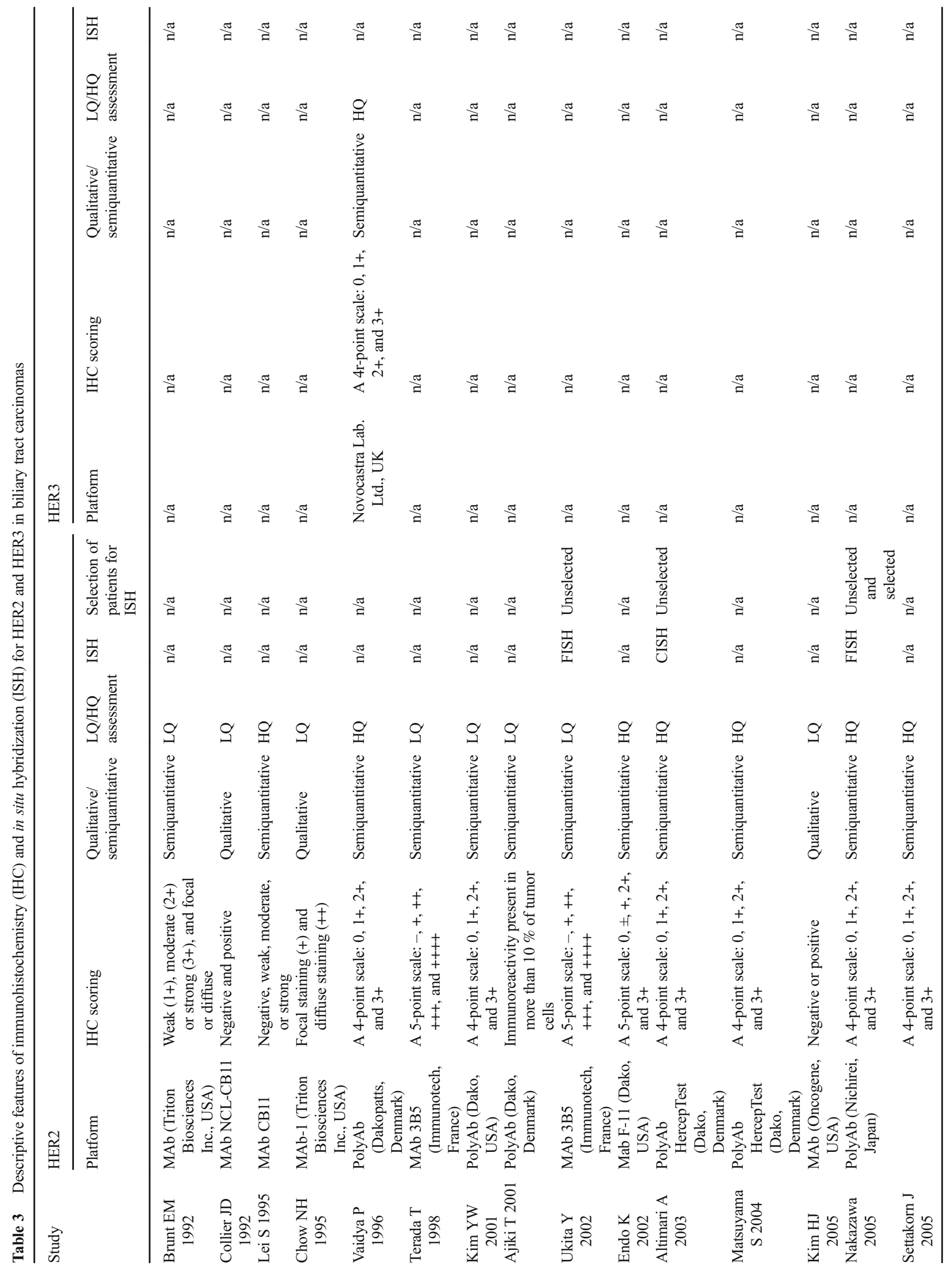




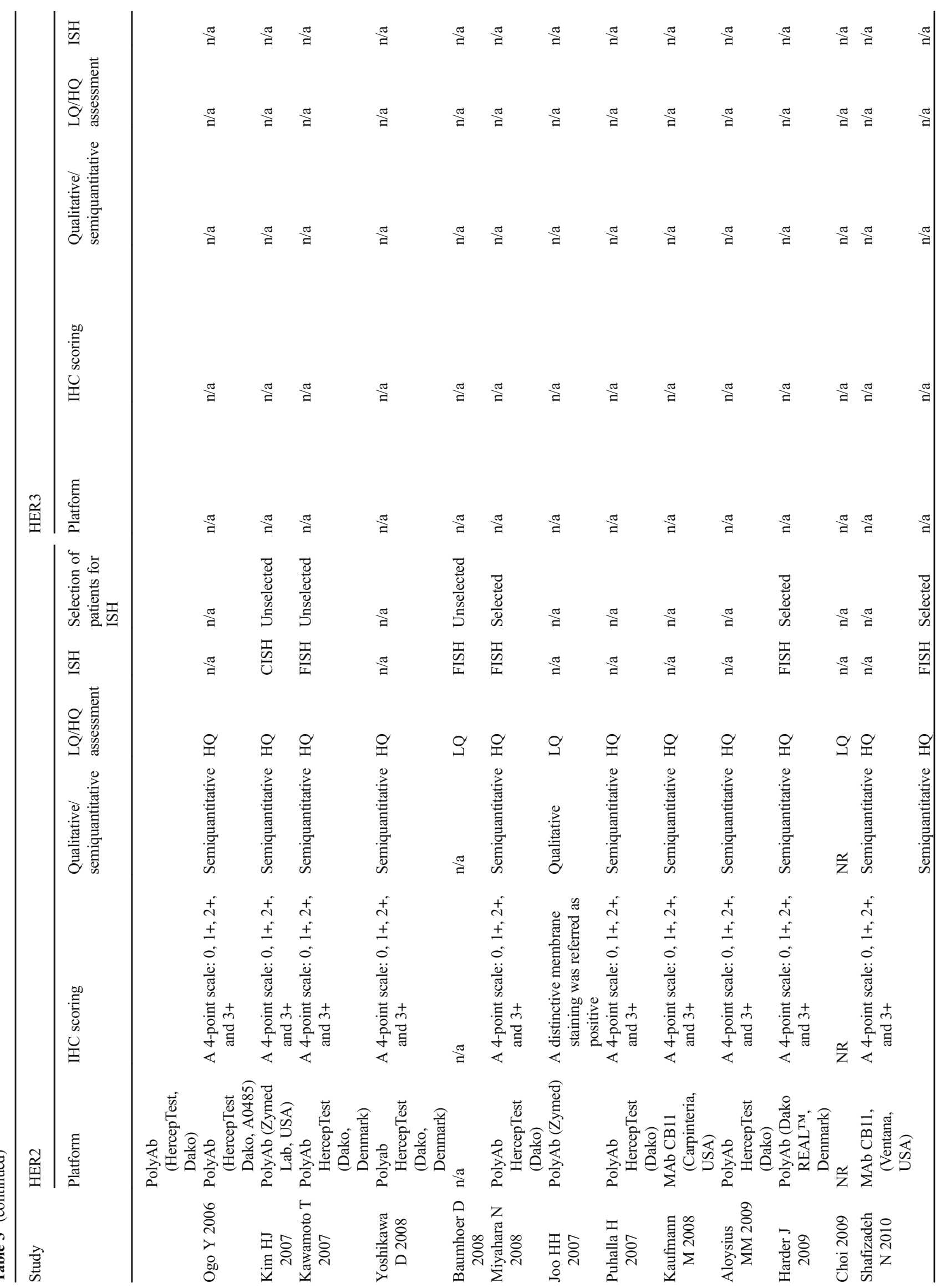




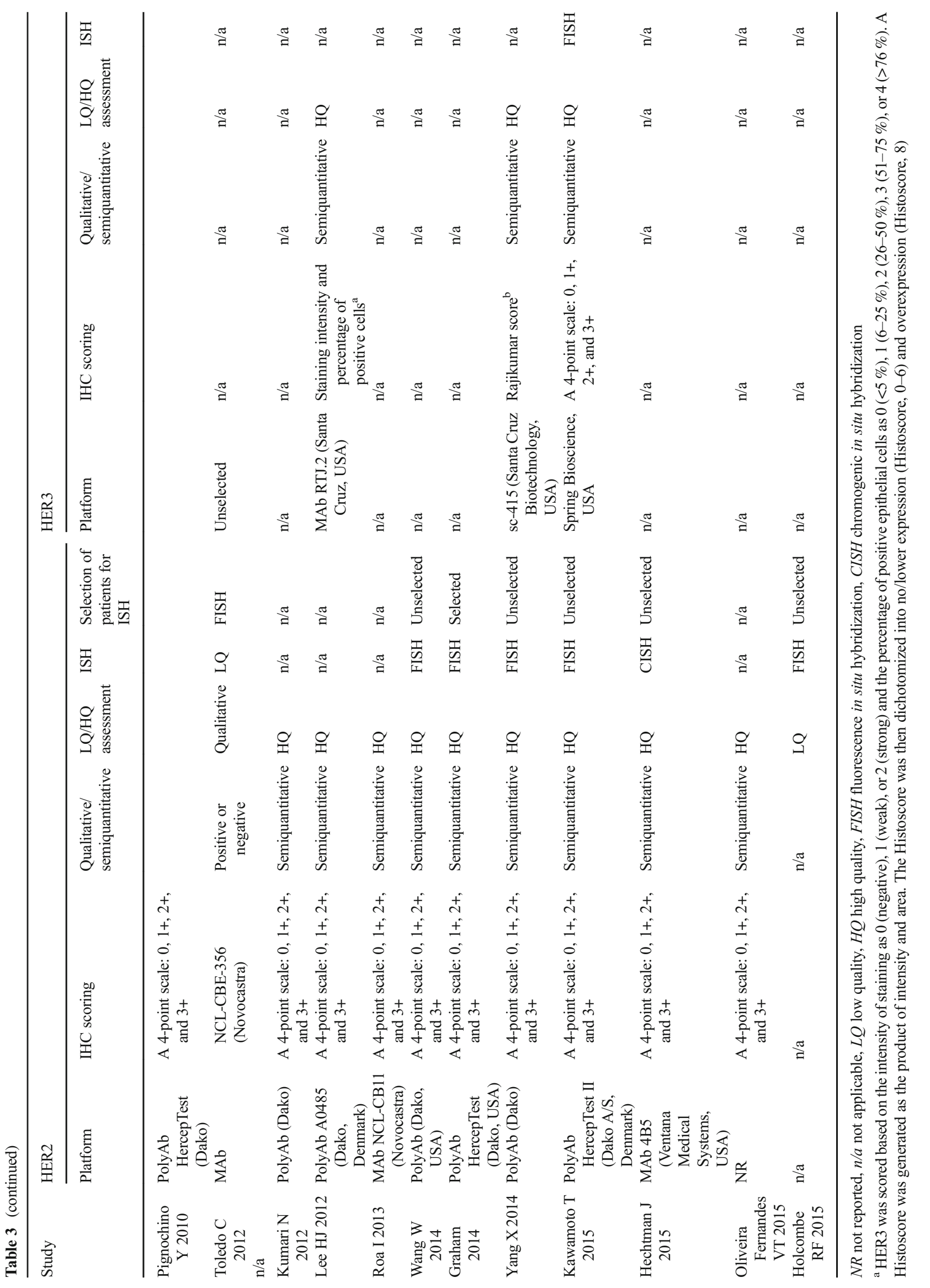


Table 4 HER2 expression and amplification results in biliary tract carcinomas

\begin{tabular}{|c|c|c|c|c|}
\hline HER2 status & & $\begin{array}{l}\text { No. of } \\
\text { studies }\end{array}$ & $\begin{array}{l}\text { Expression rate mean (95\% } \\
\text { CI, \%) }\end{array}$ & $\begin{array}{l}p \\
\text { value }\end{array}$ \\
\hline Overall expression by IHC & All & 38 & $26.5 \%(18.9-34.1 \%)$ & \\
\hline \multirow[t]{2}{*}{ By ethnicity } & Asian & 17 & $28.4 \%(14.5-42.3 \%)$ & Ref \\
\hline & Western & 16 & $19.7 \%(10.1-29.2 \%)$ & 0.4936 \\
\hline \multirow[t]{2}{*}{ By IHC assessment (quality) } & $\begin{array}{l}\text { Low quality } \\
\text { (LQ) }\end{array}$ & 11 & $41.7 \%(22.9-60.5 \%)$ & Ref \\
\hline & $\begin{array}{l}\text { High quality } \\
\text { (HQ) }\end{array}$ & 27 & $20.3 \%(13.2-27.5 \%)$ & 0.0336 \\
\hline \multirow{5}{*}{$\begin{array}{l}\text { By site of primary (HQ studies } \\
\text { only) }\end{array}$} & IHCC & 8 & $4.8 \%(0-14.5 \%)$ & Ref \\
\hline & EH-BTC & 28 & $19.9 \%(12.8-27.1 \%)$ & 0.0049 \\
\hline & $\mathrm{EHCC}$ & 11 & $17.4 \%(3.4-31.4 \%)$ & 0.0134 \\
\hline & GBC & 12 & $19.1 \%(11.2-26.8 \%)$ & 0.0123 \\
\hline & $\mathrm{AC}$ & 5 & $27.9 \%(0-60.7 \%)$ & 0.0642 \\
\hline Overall amplification by ISH & All & 16 & $30.1 \%(11.7-48.5 \%)$ & \\
\hline \multirow[t]{2}{*}{ By site of primary } & $\mathrm{IHCC}$ & 6 & $17.6 \%(0-60.1 \%)$ & Ref \\
\hline & EH-BTC & 14 & $22.5 \%(7.9 \%-37.2 \%)$ & 0.0468 \\
\hline \multirow[t]{2}{*}{ By patient selection } & Unselected & 12 & $17.9 \%(0.1-35.4 \%)$ & Ref \\
\hline & Selected & 5 & $57.6 \%(16.2-99 \%)$ & 0.0072 \\
\hline
\end{tabular}

$L Q$ low quality, $H Q$ high quality, ISH in situ hybridization, IHCC intrahepatic cholangiocarcinoma, EHCC extrahepatic cholangiocarcinoma, $E H-B T C s$ extrahepatic biliary tract cancers, $G B C$ gallbladder carcinoma, $A C$ ampulla of Vater carcinoma, Ref category used as reference for comparisons

Bold-italics represent statistically significant results
[86]. However, this work was based on a smaller number of studies (five) detecting HER2 expression in only IHCC and EHCC, excluding GBC and $\mathrm{AC}$, and did not provide any information about ISH testing. Subgroup analysis by site of primary in the current study suggested that HER2 overexpression was higher in EHCC, GBC, and AC tumors than in IHCCs [of note, this difference was not statistically significant between the group of IHCC and ACs, probably due to a small- er sample size of this subgroup (303 patients)].

Interestingly, in the IHC "selected population" (patients with moderate/strong expression by IHC), HER2 amplification rate was found to be $\sim 60 \%$. Therefore, these findings (moderate/strong HER2 expression rates in EH-BTCs and FISH rates in IHC "selected" patients) suggest around 10-20\% of EHBTCs can be virtually considered HER2 upregulated. In a recent case series of 211 consecutive GBC tumors, $16.6 \%$ of
Fig. 3 Correlation between HER2 expression and amplification

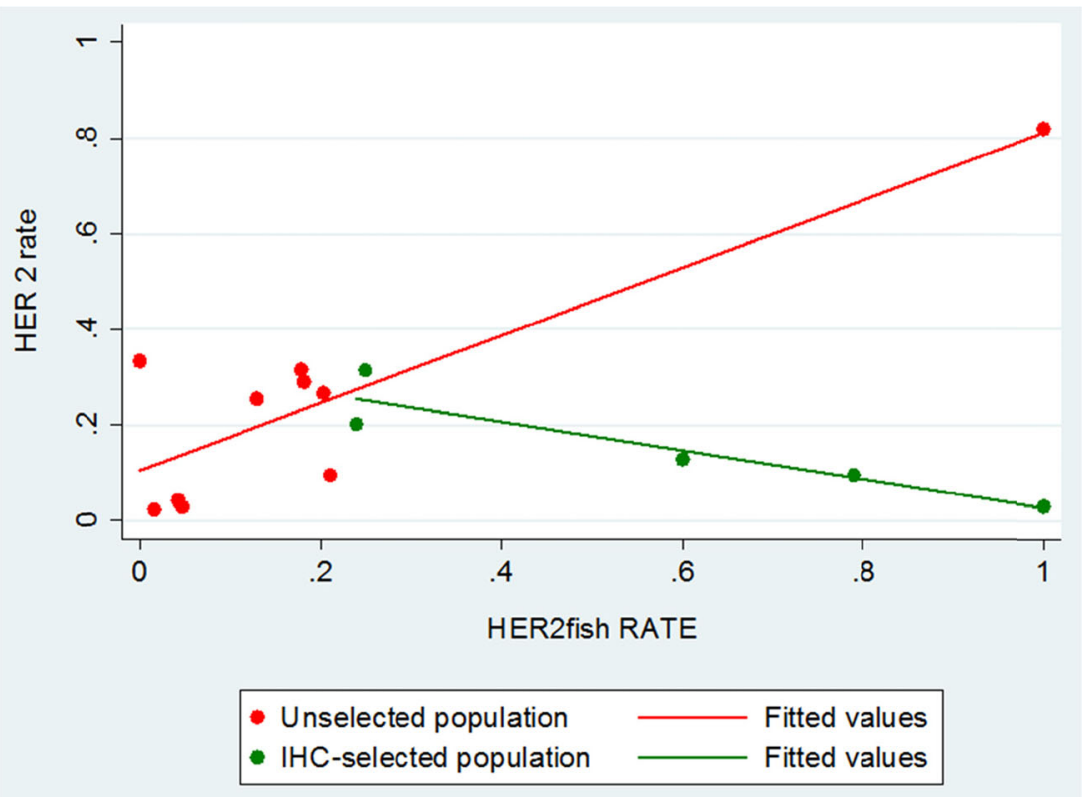


Fig. 4 Correlation between HER2 and HER3 expression

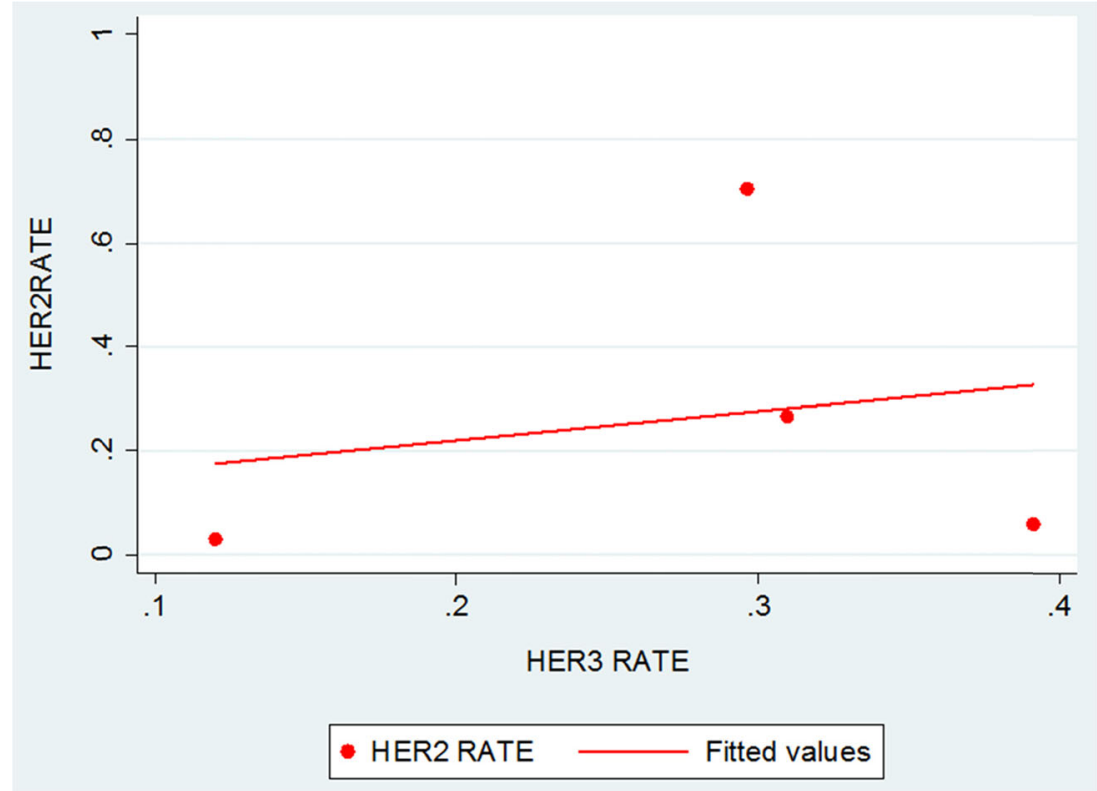

tumors were globally found to be HER2 positive when IHC3+ and IHC 2+/FISH-amplified tumors were considered altogether [87]. According to international HER 2 assessment criteria used for breast and gastric cancer $[6,26,27]$, it may be assumed that BTCs scoring $3+$ on immunohistochemistry should be interpreted as positive, while the application of in situ hybridization (fluorescence or chromogenic) could be carried out only in tumors with an ambiguous (IHC 2+) score.

These results, in addition to some preclinical data demonstrating that constitutive overexpression of activated HER2 can result in cholangiocarcinoma development [88], provide some support that the HER2 protein may play an important role in extrahepatic biliary carcinogenesis. Consequently, the HER2 pathway may be considered as a potential actionable target in EH-BTCs. Inhibition of HER2-mediated signaling is an established therapeutic strategy in HER2-positive breast and gastric cancer in which HER2 overexpression rates (up to $20 \%$ ) are similar to that found in EH-BTCs [26, 89]. AntiHER2 therapy options might include the antibodies trastuzumab, pertuzumab, or trastuzumab emtansine (T-DM1) or the small-molecule, orally active, TKI, lapatinib [6, 90, 91].

Beyond HER2, in BTC, other biomarkers might be involved in cancer pathogenesis, prognosis, and resistance to therapy. In the current meta-analysis, approximately one in four patients had moderate/strong expression of HER3 or HER3 gene amplification. Most interestingly, HER2/HER3 co-expression in BTCs ranges from 9 to $53 \%$ [76, 83] and has been demonstrated to be frequently associated with phosphorylation (activation) of HER2 and AKT [83]. HER3 is often correlated with poorly differentiated biliary tumors [81] and appears to be a poor prognostic factor in EHCCs [76], whereas the prognostic meaning of HER2 has not been completely clarified $[79,87]$. Interestingly, the combination of pertuzumab and trastuzumab has been reported to induce a synergistic inhibition of in vivo tumor growth in BTCs, likely because of a more comprehensive blockade of HER2/HER3 signaling [83]. Moreover, HER4 was found to be overexpressed in $63.1 \%$ of IHCCs and in $56.4 \%$ of EHCCs, respectively, demonstrating to be a significant poor prognostic factor in EGFR-negative IHCC cases [81]. KRAS/ NRAS mutations occur in $6.1-6.5 \%$ of BTCs $[73,82,85]$ and they appear to be mutually exclusive with HER2 amplification, at least in ACs [82]. Less frequently, BTCs harbor BRAF mutations $(0-8.1 \%)$ or PI3K mutations $(7.3-10.2 \%)$ [73, 82], while MET expression measured by IHC ranges from 5.6 to $44.1 \%$ [54, 59, 62]. Importantly, investigational research should mainly define magnitude and prognostic impact of these biomarkers in BTCs and their correlation with HER2/ HER3 pathway.

Therefore, due to inherent anatomical and molecular features, BTCs should no longer be classified as a singular entity and, in the future, differences in tumor location or tumor biology as well as an accurate distinction from other neoplastic entities should be carefully considered so as to minimize disappointing results in both clinical practice and scientific research.

This systematic review and meta-analysis has limitations, mainly linked to inter-study heterogeneity. In several studies, a clear definition of the primary tumor site was not available or results were not reported separately for each subgroup, thus limiting the eligible data for inclusion in subgroup analyses. Since no standardized techniques and scores to assess HER2 amplification and expression are available in BTCs, and because there are no internationally accepted and validated methods for HER3 testing established in any tumor, inconsistency in methodology may be an issue. Furthermore, the 
articles included in this meta-analysis covered a long period of time (1992 to 2015), and thus various laboratory assays were likely utilized to determine HER2 protein expression and gene amplification with different cutoff values for positivity employed. Differences in methodology, disease stage (early vs. advanced), tumor specimen (resection specimen vs. biopsy), site of tumor specimen (primary vs. metastases), IHC scoring system (qualitative vs. semiquantitative), threshold definition of IHC overexpression (provided vs. not), and/or choice of tumors in which the ISH test was applied (HER2 overexpression vs. no overexpression) may explain the wide range of both HER2 expression (0 to $82 \%$ ) and amplification ( 0 to $100 \%$ ) positivity reported in this review. Moreover, available literature indicates a certain variability between polyclonal and monoclonal antibodies in the ability to detect membranous HER2 protein, a higher level of concordance between IHC and ISH for polyclonal antibodies, and the possibility of influencing antigen retrieval through utilization of various application methods on tissue samples [92]. Due to the characteristics of the data reported, it was not possible to perform analysis of co-expression rate between HER2 and HER3 or concordance between IHC and ISH. Finally, no survival data was available, making it impossible to assess the prognostic implications of HER2/HER3 expression/amplification.

Despite the abovementioned limitations, this metaanalysis is the first study to systematically estimate the prevalence of HER2 and HER3 in all BTCs. Approximately one fifth of EH-BTCs are HER2 overexpressed, suggesting that the development of strategies against this receptor could be a reasonable therapeutic approach. Further data is required regarding the impact of co-expression of both HER2 and HER3. Standardization of ISH and IHC techniques, validation of scoring criteria for HER2 and HER3 immunohistochemistry, and assessment of concordance between IHC and ISH, focusing on the high intra-tumoral heterogeneity of HER 2 membranous protein [87], are needed if the techniques are to be adopted to clinical practice. Assuming that an overexpression of HER 2 of $5 \%$ or less could be considered "un-interesting," in this era of personalized medicine and spending review, our data may be particularly pertinent for the most costeffective selection of patients with BTCs who may benefit from anti-HER2-targeted therapy.

Well-designed prospective clinical trials, for patients rigorously selected by HER2-positive tumors and, possibly, stratified by tumor location, are warranted to confirm the benefit of adding anti-HER2-targeted agents to chemotherapy in advanced disease. Given the lack of benefit reported for lapatinib in previous phase II trials in BTCs [93, 94] as well as in phase III trials in HER2-positive advanced gastric cancer [95, 96], alternative anti-HER2 therapies such as monoclonal antibodies trastuzumab and pertuzumab seem to be more promising.
Acknowledgements We would like to express our gratitude to Mr. Russell Edu Samuel William for his help with literature research and Mr. Daniele Maffeis for scientific figure designing (applicable to Fig. 1).

Contribution of each author SG and JV formulated the research question. SG, AL, and JV were responsible for the study design. SG collected the data. AL analyzed the data. All authors interpreted and wrote the manuscript.

\section{Compliance with ethical standards}

Conflict of interest Authors declare no conflict of interest.

Funding Salvatore Galdy is part-funded by "Clinical Unit Visit" European Society of Medical Oncology (ESMO) Fellowship.

Angela Lamarca is part-funded by Pancreatic Cancer Research Fund (PCRF) Grant and Spanish Society of Medical Oncology (SEOM) Translational Fellowship Grant.

Open Access This article is distributed under the terms of the Creative Commons Attribution 4.0 International License (http:// creativecommons.org/licenses/by/4.0/), which permits unrestricted use, distribution, and reproduction in any medium, provided you give appropriate credit to the original author(s) and the source, provide a link to the Creative Commons license, and indicate if changes were made.

\section{References}

1. Valle, J., Wasan, H., Palmer, D. H., Cunningham, D., Anthoney, A., Maraveyas, A., et al. (2010). Cisplatin plus gemcitabine versus gemcitabine for biliary tract cancer. The New England Journal of Medicine, 362(14), 1273-1281.

2. Valle, J. W., Furuse, J., Jitlal, M., Beare, S., Mizuno, N., Wasan, H., et al. (2014). Cisplatin and gemcitabine for advanced biliary tract cancer: a meta-analysis of two randomised trials. Annals of Oncology: Official Journal of the European Society for Medical Oncology / ESMO, 25(2), 391-398.

3. Merla, A., Liu, K. G., \& Rajdev, L. (2015). Targeted therapy in biliary tract cancers. Current Treatment Options in Oncology, 16(10), 48. doi:10.1007/s11864-015-0366-0.

4. Valle, J. W., Wasan, H., Lopes, A., Backen, A. C., Palmer, D. H., Morris, K., et al. (2015). Cediranib or placebo in combination with cisplatin and gemcitabine chemotherapy for patients with advanced biliary tract cancer (ABC-03): a randomised phase 2 trial. The Lancet.Oncology, 16(8), 967-978.

5. Slamon, D. J., Leyland-Jones, B., Shak, S., Fuchs, H., Paton, V., Bajamonde, A., et al. (2001). Use of chemotherapy plus a monoclonal antibody against HER2 for metastatic breast cancer that overexpresses HER2. The New England Journal of Medicine, 344(11), 783-792.

6. Bang, Y. J., Van Cutsem, E., Feyereislova, A., Chung, H. C., Shen, L., Sawaki, A., et al. (2010). Trastuzumab in combination with chemotherapy versus chemotherapy alone for treatment of HER2positive advanced gastric or gastro-oesophageal junction cancer (ToGA): a phase 3, open-label, randomised controlled trial. Lancet (London, England), 376(9742), 687-697.

7. Law, L. Y. (2012). Dramatic response to trastuzumab and paclitaxel in a patient with human epidermal growth factor receptor 2-positive metastatic cholangiocarcinoma. Journal of Clinical Oncology: Official Journal of the American Society of Clinical Oncology, 30(27), e271-e273. 
8. Sorscher, S. (2013). Marked radiographic response of a HER-2overexpressing biliary cancer to trastuzumab. Cancer Management and Research, 9, 1-3.

9. Subbiah, I. M., Subbiah, V., Tsimberidou, A. M., Naing, A., Kaseb, A. O., Javle, M., et al. (2013). Targeted therapy of advanced gallbladder cancer and cholangiocarcinoma with aggressive biology: eliciting early response signals from phase 1 trials. Oncotarget, 4(1), 153-162.

10. Javle, M., Churi, C., Kang, H. C., Shroff, R., Janku, F., Surapaneni, R., et al. (2015). HER2/neu-directed therapy for biliary tract cancer. Journal of Hematology \& Oncology, 8, 58. doi:10.1186/s13045015-0155-z.

11. Lee, J., Park, S. H., Chang, H. M., Kim, J. S., Choi, H. J., Lee, M. A., et al. (2012). Gemcitabine and oxaliplatin with or without erlotinib in advanced biliary-tract cancer: a multicentre, open-label, randomised, phase 3 study. The Lancet.Oncology, 13(2), 181-188.

12. Chen, J. S., Hsu, C., Chiang, N. J., Tsai, C. S., Tsou, H. H., Huang, S. F., et al. (2015). A KRAS mutation status-stratified randomized phase II trial of gemcitabine and oxaliplatin alone or in combination with cetuximab in advanced biliary tract cancer. Annals of Oncology: Official Journal of the European Society for Medical Oncology / ESMO, 26(5), 943-949.

13. Malka, D., Cervera, P., Foulon, S., Trarbach, T., de la Fouchardiere, C., Boucher, E., et al. (2014). Gemcitabine and oxaliplatin with or without cetuximab in advanced biliary-tract cancer (BINGO): a randomised, open-label, non-comparative phase 2 trial. The Lancet.Oncology, 15(8), 819-828.

14. Leone, F., Marino, D., Cereda, S., Filippi, R., Belli, C., Spadi, R., et al. (2016). Panitumumab in combination with gemcitabine and oxaliplatin does not prolong survival in wild-type KRAS advanced biliary tract cancer: a randomized phase 2 trial (vecti-BIL study). Cancer, 122(4), 574-581.

15. Zhang, H., Berezov, A., Wang, Q., Zhang, G., Drebin, J., Murali, R., et al. (2007). ErbB receptors: from oncogenes to targeted cancer therapies. The Journal of Clinical Investigation, 117(8), 20512058.

16. Garrett, T. P., McKern, N. M., Lou, M., Elleman, T. C., Adams, T. E., Lovrecz, G. O., et al. (2003). The crystal structure of a truncated ErbB2 ectodomain reveals an active conformation, poised to interact with other ErbB receptors. Molecular Cell, 11(2), 495-505.

17. Hudis, C. A. (2007). Trastuzumab-mechanism of action and use in clinical practice. The New England Journal of Medicine, 357(1), 39-51.

18. Hynes, N. E., \& Lane, H. A. (2005). ERBB receptors and cancer: the complexity of targeted inhibitors. Nature Reviews Cancer, 5(5), 341-354.

19. Graus-Porta, D., Beerli, R. R., Daly, J. M., \& Hynes, N. E. (1997). ErbB-2, the preferred heterodimerization partner of all ErbB receptors, is a mediator of lateral signaling. The EMBO Journal, 16(7), $1647-1655$.

20. Baselga, J., \& Swain, S. M. (2009). Novel anticancer targets: revisiting ERBB2 and discovering ERBB3. Nature Reviews Cancer, 9(7), 463-475.

21. Sierke, S. L., Cheng, K., Kim, H. H., \& Koland, J. G. (1997). Biochemical characterization of the protein tyrosine kinase homology domain of the ErbB3 (HER3) receptor protein. The Biochemical Journal, 322(Pt 3), 757-763.

22. Tzahar, E., Waterman, H., Chen, X., Levkowitz, G., Karunagaran, D., Lavi, S., et al. (1996). A hierarchical network of interreceptor interactions determines signal transduction by neu differentiation factor/neuregulin and epidermal growth factor. Molecular and Cellular Biology, 16(10), 5276-5287.

23. Amin, D. N., Sergina, N., Ahuja, D., McMahon, M., Blair, J. A., Wang, D., et al. (2010). Resiliency and vulnerability in the HER2HER3 tumorigenic driver. Science Translational Medicine, 2(16), 16 ra7.
24. Engelman, J. A., Zejnullahu, K., Mitsudomi, T., Song, Y., Hyland, C., Park, J. O., et al. (2007). MET amplification leads to gefitinib resistance in lung cancer by activating ERBB3 signaling. Science (New York, N.Y.), 316(5827), 1039-1043.

25. Choi, B. K., Fan, X., Deng, H., Zhang, N., \& An, Z. (2012). ERBB3 (HER3) is a key sensor in the regulation of ERBBmediated signaling in both low and high ERBB2 (HER2) expressing cancer cells. Cancer Medicine, 1(1), 28-38.

26. Wolff, A. C., Hammond, M. E., Hicks, D. G., Dowsett, M., McShane, L. M., Allison, K. H., et al. (2013). Recommendations for human epidermal growth factor receptor 2 testing in breast cancer: American Society of Clinical Oncology/College of American Pathologists clinical practice guideline update. Journal of Clinical Oncology: Official Journal of the American Society of Clinical Oncology, 31(31), 3997-4013.

27. Hofmann, M., Stoss, O., Shi, D., Buttner, R., van de Vijver, M., Kim, W., et al. (2008). Assessment of a HER2 scoring system for gastric cancer: results from a validation study. Histopathology, 52(7), 797-805.

28. Moher, D., Liberati, A., Tetzlaff, J., Altman, D. G., \& PRISMA Group. (2009). Preferred reporting items for systematic reviews and meta-analyses: the PRISMA statement. Open Medicine: A Peer-Reviewed, Independent, Open-Access Journal, 3(3), e123-e130.

29. Voravud, N., Foster, C. S., Gilbertson, J. A., Sikora, K., \& Waxman, J. (1989). Oncogene expression in cholangiocarcinoma and in normal hepatic development. Human Pathology, 20(12), 1163-1168.

30. Vaidya, P., Yosida, T., Sakakura, T., Yatani, R., Noguchi, T., \& Kawarada, Y. (1996). Combined analysis of expression of c-erbB2, ki-67 antigen, and tenascin provides a better prognostic indicator of carcinoma of the papilla of vater. Pancreas, 12(2), 196-201.

31. Kamel, D., Paakko, P., Nuorva, K., Vahakangas, K., \& Soini, Y. (1993). p53 and c-erbB-2 protein expression in adenocarcinomas and epithelial dysplasias of the gall bladder. The Journal of Pathology, 170(1), 67-72.

32. Yukawa, M., Fujimori, T., Hirayama, D., Idei, Y., Ajiki, T., Kawai, K., et al. (1993). Expression of oncogene products and growth factors in early gallbladder cancer, advanced gallbladder cancer, and chronic cholecystitis. Human Pathology, 24(1), 37-40.

33. Suzuki, H., Isaji, S., Pairojkul, C., \& Uttaravichien, T. (2000). Comparative clinicopathological study of resected intrahepatic cholangiocarcinoma in northeast Thailand and Japan. Journal of Hepato-Biliary-Pancreatic Surgery, 7(2), 206-211.

34. Aishima, S. I., Taguchi, K. I., Sugimachi, K., Shimada, M., Sugimachi, K., \& Tsuneyoshi, M. (2002). c-erbB-2 and c-met expression relates to cholangiocarcinogenesis and progression of intrahepatic cholangiocarcinoma. Histopathology, 40(3), 269-278.

35. Kalekou, H., \& Miliaras, D. (2004). Immunohistochemical study of microvessel density, CD44 (standard form), p53 protein and cerbB2 in gallbladder carcinoma. Journal of Gastroenterology and Hepatology, 19(7), 812-818.

36. Chaube, A., Tewari, M., Garbyal, R. S., Singh, U., \& Shukla, H. S. (2006). Preliminary study of p53 and c-erbB-2 expression in gallbladder cancer in indian patients manuscript id: 8962091628764582. BMC Cancer, 6, 126.

37. Zheng, J., \& Zhu, Y. M. (2007). Expression of c-erbB-2 protooncogene in extrahepatic cholangiocarcinoma and its clinical significance. Hepatobiliary \& Pancreatic Diseases International: HBPD INT, 6(4), 412-415.

38. Schlitter, A. M., Jang, K. T., Kloppel, G., Saka, B., Hong, S. M., Choi, H., et al. (2015). Intraductal tubulopapillary neoplasms of the bile ducts: clinicopathologic, immunohistochemical, and molecular analysis of 20 cases. Modern Pathology: An Official Journal of the United States and Canadian Academy of Pathology, Inc, 28(9), $1249-1264$. 
39. Ito, Y., Takeda, T., Sasaki, Y., Sakon, M., Yamada, T., Ishiguro, S., et al. (2001). Expression and clinical significance of the erbB family in intrahepatic cholangiocellular carcinoma. Pathology, Research and Practice, 197(2), 95-100.

40. Andersen, J. B., Spee, B., Blechacz, B. R., Avital, I., Komuta, M., Barbour, A., et al. (2012). Genomic and genetic characterization of cholangiocarcinoma identifies therapeutic targets for tyrosine kinase inhibitors. Gastroenterology, 142(4), 1021-1031 e15.

41. Maurya, S. K., Tewari, M., Sharma, B., \& Shukla, H. S. (2013). Expression of procaspase 3 and activated caspase 3 and its relevance in hormone-responsive gallbladder carcinoma chemotherapy. The Korean Journal of Internal Medicine, 28(5), 573-578.

42. Suder, A., Ang, J. E., Kyle, F., Harris, D., Rudman, S., Kristeleit, R., et al. (2015). A phase I study of daily afatinib, an irreversible ErbB family blocker, in combination with weekly paclitaxel in patients with advanced solid tumours. European Journal of Cancer (Oxford, England: 1990), 51(16), 2275-2284.

43. Euscher, E. D., Marsh Jr., W. L., Lucas, J. G., \& Frankel, W. L. (2007). Histologic and immunohistochemical changes in the stented common bile duct. Applied Immunohistochemistry \& Molecular Morphology: AIMM / Official Publication of the Society for Applied Immunohistochemistry, 15(3), 299-304.

44. Zhu, L., Kim, K., Domenico, D. R., Appert, H. E., \& Howard, J. M. (1996). Adenocarcinoma of duodenum and ampulla of vater: clinicopathology study and expression of p53, c-neu, TGF-alpha, CEA, and EMA. Journal of Surgical Oncology, 61(2), 100-105.

45. Ooi, A., Suzuki, S., Nakazawa, K., Itakura, J., Imoto, I., Nakamura, H., et al. (2009). Gene amplification of myc and its coamplification with ERBB2 and EGFR in gallbladder adenocarcinoma. Anticancer Research, 29(1), 19-26.

46. Ajiki, T., Kamigaki, T., Hasegawa, Y., Fujino, Y., Suzuki, Y., Takeyama, Y., et al. (2001). Proliferating cell nuclear antigen, $\mathrm{p} 53$, and c-erbB-2 expression in relation to clinicopathological variables and prognosis in cancer of the ampulla of Vater. HepatoGastroenterology, 48(41), 1266-1270.

47. Brunt, E. M., \& Swanson, P. E. (1992). Immunoreactivity for cerbB-2 oncopeptide in benign and malignant diseases of the liver. American Journal of Clinical Pathology, 97(5 Suppl 1), S53-S61.

48. Collier, J. D., Guo, K., Mathew, J., May, F. E., Bennett, M. K., Corbett, I. P., et al. (1992). c-erbB-2 oncogene expression in hepatocellular carcinoma and cholangiocarcinoma. Journal of Hepatology, 14(2-3), 377-380.

49. Chow, N. H., Huang, S. M., Chan, S. H., Mo, L. R., Hwang, M. H., $\& \mathrm{Su}$, W. C. (1995). Significance of c-erbB-2 expression in normal and neoplastic epithelium of biliary tract. Anticancer Research, 15(3), 1055-1059.

50. Lei, S., Appert, H. E., Nakata, B., Domenico, D. R., Kim, K., \& Howard, J. M. (1995). Overexpression of HER2/neu oncogene in pancreatic cancer correlates with shortened survival. International Journal of Pancreatology: Official Journal of the International Association of Pancreatology, 17(1), 15-21.

51. Vaidya, P., Kawarada, Y., Higashiguchi, T., Yoshida, T., Sakakura, T., \& Yatani, R. (1996). Overexpression of different members of the type 1 growth factor receptor family and their association with cell proliferation in periampullary carcinoma. The Journal of Pathology, 178(2), 140-145.

52. Terada, T., Ashida, K., Endo, K., Horie, S., Maeta, H., Matsunaga, Y., et al. (1998). c-erbB-2 protein is expressed in hepatolithiasis and cholangiocarcinoma. Histopathology, 33(4), 325-331.

53. Kim, Y. W., Huh, S. H., Park, Y. K., Yoon, T. Y., Lee, S. M., \& Hong, S. H. (2001). Expression of the c-erb-B2 and p53 protein in gallbladder carcinomas. Oncology Reports, 8(5), 1127-1132.

54. Endo, K., Yoon, B. I., Pairojkul, C., Demetris, A. J., \& Sirica, A. E. (2002). ERBB-2 overexpression and cyclooxygenase-2 up-regulation in human cholangiocarcinoma and risk conditions. Hepatology (Baltimore, Md.), 36(2), 439-450.
55. Ukita, Y., Kato, M., \& Terada, T. (2002). Gene amplification and mRNA and protein overexpression of c-erbB-2 (HER-2/neu) in human intrahepatic cholangiocarcinoma as detected by fluorescence in situ hybridization, in situ hybridization, and immunohistochemistry. Journal of Hepatology, 36(6), 780-785.

56. Altimari, A., Fiorentino, M., Gabusi, E., Gruppioni, E., Corti, B., D'Errico, A., et al. (2003). Investigation of ErbB1 and ErbB2 expression for therapeutic targeting in primary liver tumours. Digestive and Liver Disease: Official Journal of the Italian Society of Gastroenterology and the Italian Association for the Study of the Liver, 35(5), 332-338.

57. Matsuyama, S., Kitajima, Y., Sumi, K., Mori, D., Satoh, T., \& Miyazaki, K. (2004). Gallbladder cancers rarely overexpress HER-2/neu, demonstrated by Hercep test. Oncology Reports, 11(4), 815-819.

58. Kim, H. J., Kim, J. S., Kang, C. D., Lee, S. J., Kim, J. Y., Yeon, J. E., et al. (2005). Expression of epidermal growth factor receptor, ErbB2 and matrix metalloproteinase-9 in hepatolithiasis and cholangiocarcinoma. The Korean Journal of Gastroenterology $=$ Taehan Sohwagi Hakhoe Chi, 45(1), 52-59.

59. Nakazawa, K., Dobashi, Y., Suzuki, S., Fujii, H., Takeda, Y., \& Ooi, A. (2005). Amplification and overexpression of c-erbB-2, epidermal growth factor receptor, and c-met in biliary tract cancers. The Journal of Pathology, 206(3), 356-365.

60. Settakorn, J., Kaewpila, N., Burns, G. F., \& Leong, A. S. (2005). FAT, E-cadherin, beta catenin, HER 2/neu, Ki67 immuno-expression, and histological grade in intrahepatic cholangiocarcinoma. Journal of Clinical Pathology, 58(12), 1249-1254.

61. Ogo, Y., Nio, Y., Yano, S., Toga, T., Koike, M., Hashimoto, K., et al. (2006). Immunohistochemical expression of HER-1 and HER-2 in extrahepatic biliary carcinoma. Anticancer Research, 26(1B), 763-770.

62. Joo, H. H., Song, E. Y., Jin, S. H., Oh, S. H., \& Choi, Y. K. (2007). Expressions and clinical significances of c-met, c-erbB-2, COX-2, and IL-6 in the biliary tract cancers. The Korean Journal of Gastroenterology = Taehan Sohwagi Hakhoe Chi, 50(6), 370-378.

63. Kawamoto, T., Krishnamurthy, S., Tarco, E., Trivedi, S., Wistuba, I. I., Li, D., et al. (2007). HER receptor family: novel candidate for targeted therapy for gallbladder and extrahepatic bile duct cancer. Gastrointestinal Cancer Research: GCR, 1(6), 221-227.

64. Kim, H. J., Yoo, T. W., Park, D. I., Park, J. H., Cho, Y. K., Sohn, C. I., et al. (2007). Gene amplification and protein overexpression of HER-2/neu in human extrahepatic cholangiocarcinoma as detected by chromogenic in situ hybridization and immunohistochemistry: its prognostic implication in node-positive patients. Annals of Oncology: Official Journal of the European Society for Medical Oncology / ESMO, 18(5), 892-897.

65. Puhalla, H., Wrba, F., Kandioler, D., Lehnert, M., Huynh, A., Gruenberger, T., et al. (2007). Expression of p21(Wafl/Cip1), p57(Kip2) and HER2/neu in patients with gallbladder cancer. Anticancer Research, 27(3B), 1679-1684.

66. Baumhoer, D., Zlobec, I., Tornillo, L., Dietmaier, W., Wuensch, P. H., Hartmann, A., et al. (2008). Immunophenotyping and oncogene amplifications in tumors of the papilla of Vater. Virchows Archiv: An International Journal of Pathology, 453(6), 579-588.

67. Kaufman, M., Mehrotra, B., Limaye, S., White, S., Fuchs, A., Lebowicz, Y., et al. (2008). EGFR expression in gallbladder carcinoma in North America. International Journal of Medical Sciences, 5(5), 285-291.

68. Miyahara, N., Shoda, J., Ishige, K., Kawamoto, T., Ueda, T., Taki, R., et al. (2008). MUC4 interacts with ErbB2 in human gallbladder carcinoma: potential pathobiological implications. European Journal of Cancer (Oxford, England: 1990), 44(7), 1048-1056.

69. Yoshikawa, D., Ojima, H., Iwasaki, M., Hiraoka, N., Kosuge, T., Kasai, S., et al. (2008). Clinicopathological and prognostic 
significance of EGFR, VEGF, and HER2 expression in cholangiocarcinoma. British Journal of Cancer, 98(2), 418-425.

70. Aloysius, M. M., Lobo, D. N., Rowlands, B. J., Madhusudan, S., Ilyas, M., \& Zaitoun, A. M. (2009). HER-2/neu overexpression is a rare event in peri-ampullary cancer: assessment using the HercepTest. Histopathology, 55(2), 236-237.

71. Choi, H. J., Kim, H. J., \& Choi, J. H. (2009). Expression of c-erbB2 and cyclooxygenase-2 in intrahepatic cholangiocarcinoma. Hepato-Gastroenterology, 56(91-92), 606-609.

72. Harder, J., Waiz, O., Otto, F., Geissler, M., Olschewski, M., Weinhold, B., et al. (2009). EGFR and HER2 expression in advanced biliary tract cancer. World Journal of Gastroenterology, 15(36), 4511-4517.

73. Pignochino, Y., Sarotto, I., Peraldo-Neia, C., Penachioni, J. Y., Cavalloni, G., Migliardi, G., et al. (2010). Targeting EGFR/HER2 pathways enhances the antiproliferative effect of gemcitabine in biliary tract and gallbladder carcinomas. BMC Cancer, 10, 631. doi:10.1186/1471-2407-10-631.

74. Shafizadeh, N., Grenert, J. P., Sahai, V., \& Kakar, S. (2010). Epidermal growth factor receptor and HER-2/neu status by immunohistochemistry and fluorescence in situ hybridization in adenocarcinomas of the biliary tree and gallbladder. Human Pathology, 41(4), 485-492.

75. Kumari, N., Kapoor, V. K., Krishnani, N., Kumar, K., \& Baitha, D. K. (2012). Role of C-erbB2 expression in gallbladder cancer. Indian Journal of Pathology \& Microbiology, 55(1), 75-79.

76. Lee, H. J., Chung, J. Y., Hewitt, S. M., Yu, E., \& Hong, S. M. (2012). HER3 overexpression is a prognostic indicator of extrahepatic cholangiocarcinoma. Virchows Archiv: An International Journal of Pathology, 461(5), 521-530.

77. Toledo, C., Matus, C. E., Barraza, X., Arroyo, P., Ehrenfeld, P., Figueroa, C. D., et al. (2012). Expression of HER2 and bradykinin $\mathrm{B}(1)$ receptors in precursor lesions of gallbladder carcinoma. World Journal of Gastroenterology, 18(11), 1208-1215.

78. Graham, R. P., Barr Fritcher, E. G., Pestova, E., Schulz, J., Sitailo, L. A., Vasmatzis, G., et al. (2014). Fibroblast growth factor receptor 2 translocations in intrahepatic cholangiocarcinoma. Human Pathology, 45(8), 1630-1638.

79. Roa, I., de Toro, G., Schalper, K., de Aretxabala, X., Churi, C., \& Javle, M. (2014). Overexpression of the HER2/neu gene: a new therapeutic possibility for patients with advanced gallbladder cancer. Gastrointestinal Cancer Research: GCR, 7(2), 42-48.

80. Wang, W., Zhang, J., Zhan, X., Lin, T., Yang, M., Hu, J., et al. (2014). SOX4 is associated with poor prognosis in cholangiocarcinoma. Biochemical and Biophysical Research Communications, 452(3), 614-621.

81. Yang, X., Wang, W., Wang, C., Wang, L., Yang, M., Qi, M., et al. (2014). Characterization of EGFR family gene aberrations in cholangiocarcinoma. Oncology Reports, 32(2), 700-708.

82. Hechtman, J. F., Liu, W., Sadowska, J., Zhen, L., Borsu, L., Arcila, M. E., et al. (2015). Sequencing of 279 cancer genes in ampullary carcinoma reveals trends relating to histologic subtypes and frequent amplification and overexpression of ERBB2 (HER2). Modern Pathology: An Official Journal of the United States and Canadian Academy of Pathology, Inc, 28(8), 1123-1129.

83. Kawamoto, T., Ishige, K., Thomas, M., Yamashita-Kashima, Y., Shu, S., Ishikura, N., et al. (2015). Overexpression and gene amplification of EGFR, HER2, and HER3 in biliary tract carcinomas, and the possibility for therapy with the HER2-targeting antibody pertuzumab. Journal of Gastroenterology, 50(4), 467-479.
84. Oliveira Fernandes, V.T., De Barros E, Silva, M.J., Begnami, M.D., Saito, A. (2015). Prognosis of HER2 expression in cholangiocarcinoma when evaluated using gastric cancer methodology of immunohistochemistry. Journal of Clinical Oncology, 33, 2015 (suppl; abstr e15203).

85. Holcombe, R.F, Xiu, J., Pishvaian, M.J., Millis, S.Z., Gatalica, Z., Reddy, S.K., et al. (2015). Tumor profiling of biliary tract carcinomas to reveal distinct molecular alterations and potential therapeutic targets. Journal of Clinical Oncology,33, 2015 (suppl 3; abstr 285).

86. Wiggers, J. K., Ruys, A. T., Groot Koerkamp, B., Beuers, U., ten Kate, F. J., \& van Gulik, T. M. (2014). Differences in immunohistochemical biomarkers between intra- and extrahepatic cholangiocarcinoma: a systematic review and meta-analysis. Journal of Gastroenterology and Hepatology, 29(8), 1582-1594.

87. Yoshida, H., Shimada, K., Kosuge, T., \& Hiraoka, N. (2016). A significant subgroup of resectable gallbladder cancer patients has an HER2 positive status. Virchows Archiv: An International Journal of Pathology, 468(4), 431-439.

88. Kiguchi, K., Carbajal, S., Chan, K., Beltran, L., Ruffino, L., Shen, J., et al. (2001). Constitutive expression of ErbB-2 in gallbladder epithelium results in development of adenocarcinoma. Cancer Research, 61(19), 6971-6976.

89. Wadhwa, R., Song, S., Lee, J. S., Yao, Y., Wei, Q., \& Ajani, J. A. (2013). Gastric cancer-molecular and clinical dimensions. Nature Reviews Clinical Oncology, 10(11), 643-655.

90. Senkus, E., Kyriakides, S., Ohno, S., Penault-Llorca, F., Poortmans, P., Rutgers, E., et al. (2015). Primary breast cancer: ESMO clinical practice guidelines for diagnosis, treatment and follow-up. Annals of Oncology: Official Journal of the European Society for Medical Oncology/ESMO, 26(Suppl 5), v8-30.

91. Cardoso, F., Costa, A., Norton, L., Senkus, E., Aapro, M., Andre, F., et al. (2014). ESO-ESMO 2nd international consensus guidelines for advanced breast cancer (ABC2)dagger. Annals of Oncology: Official Journal of the European Society for Medical Oncology / ESMO, 25(10), 1871-1888.

92. Press, M. F., Hung, G., Godolphin, W., \& Slamon, D. J. (1994). Sensitivity of HER-2/neu antibodies in archival tissue samples: potential source of error in immunohistochemical studies of oncogene expression. Cancer Research, 54(10), 2771-2777.

93. Ramanathan, R. K., Belani, C. P., Singh, D. A., Tanaka, M., Lenz, H. J., Yen, Y., et al. (2009). A phase II study of lapatinib in patients with advanced biliary tree and hepatocellular cancer. Cancer Chemotherapy and Pharmacology, 64(4), 777-783.

94. Peck, J., Wei, L., Zalupski, M., O'Neil, B., Villalona Calero, M., \& Bekaii-Saab, T. (2012). HER2/neu may not be an interesting target in biliary cancers: results of an early phase II study with lapatinib. Oncology, 82(3), 175-179.

95. Hecht, J. R., Bang, Y. J., Qin, S. K., Chung, H. C., Xu, J. M., Park, J. O., et al. (2016). Lapatinib in combination with capecitabine plus oxaliplatin in human epidermal growth factor receptor 2-positive advanced or metastatic gastric, esophageal, or gastroesophageal adenocarcinoma: TRIO-013/LOGiC - a randomized phase III trial. Journal of Clinical Oncology: Official Journal of the American Society of Clinical Oncology, 34(5), 443-451.

96. Satoh, T., Xu, R. H., Chung, H. C., Sun, G. P., Doi, T., Xu, J. M., et al. (2014). Lapatinib plus paclitaxel versus paclitaxel alone in the second-line treatment of HER2-amplified advanced gastric cancer in Asian populations: TyTAN - a randomized, phase III study. Journal of Clinical Oncology: Official Journal of the American Society of Clinical Oncology, 32(19), 2039-2049. 